
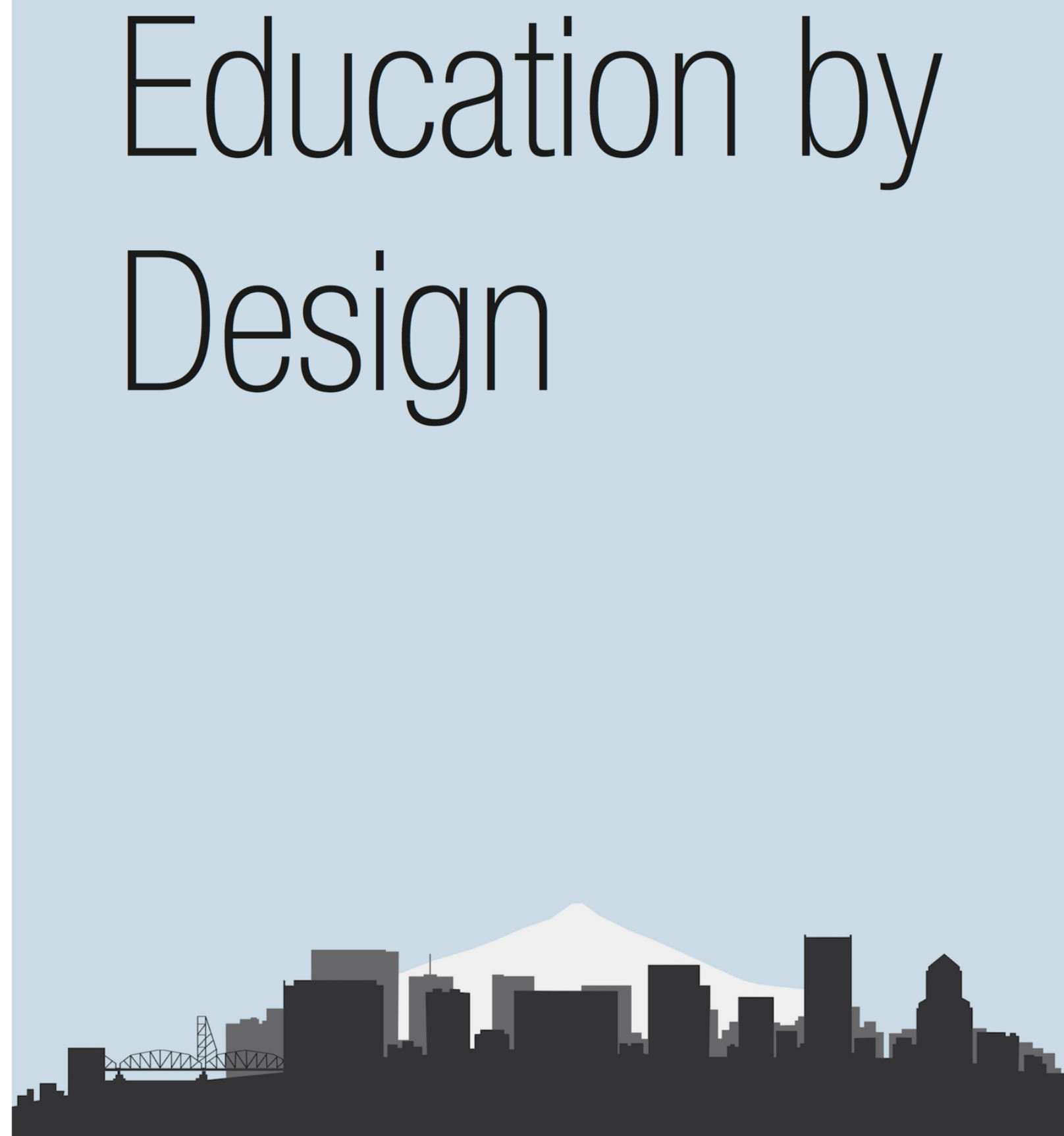

2019 Reynolds Symposium: Education by Design

October 18-20, 2019 


\section{Organizing Committee:}

[co-organizers]

Professor Alison Kwok, Ph.D, FAlA, University of Oregon

Emeritus Professor John Reynolds, FAIA, University of Oregon

[Symposium coordinator]

Isabel Rivera, Ph.D., University of Oregon

Professor Walter Grondzik, P.E., Ball State University

Professor Bruce Haglund, AIA Assoc., University of Idaho

Assistant Professor Emily McGlohn, AlA, Auburn University

Associate Professor Ulrike Passe, lowa State University

Assistant Professor Siobhan Rockcastle, Ph.D., University of Oregon

Sharon Refvem, FAIA, LEED Fellow, Senior Associate and Director, Sustainability Resource Group,

Hawley Peterson Snyder 


\title{
BUILDING THE CURVE: STRUCTURING STUDIO EDUCATION AS INTERACTIVE INCLUSION RATHER THAN CHARRETTE
}

\author{
Robert J. Koester, AIA LEED AP \\ Professor \\ Ball State University \\ Muncie, Indiana \\ rkoester@bsu.edu
}

\begin{abstract}
The challenge of design-for-sustainability is to balance the need to educate about design process as an intelligent discipline while using the content of social, economic and environmental factors as the space of design decision-making.

The legacy of studio education as a tutorial enterprise has for decades built upon the service delivery sequences used in professional practice; pre-design, programming, site selection and analysis, schematic design, design development, construction documentation, construction observation; with only occasional post occupancy evaluation.
\end{abstract}

Design-for-sustainability, however, must operate on a less sequential delivery model; employing instead a "breathing in and breathing out" functionality of parallel processing unique to the trial and error nature of the design process itself.

Fundamentally, design is an inefficient iterative process, an aspirational enterprise, and a willfully integrative act. But that integration must have multiple moorings.

Moreover, we must abandon the charrette model in favor of "building the curve" of inclusion, integrating the multiplicities within the design-decision space over time by using a rhythmic sequencing of exploration and reflection; namely, the Blue Dot technique of scripting/scheduling the activity of design exploration, introduction and application; wherein every design project becomes a form of adaptive reuse.

This presentation will share student work developed over a decade of application of the Blue Dot methodology to show highly integrative design-for-sustainability projects; as products of the intelligent balance of process and content education.

\section{INTRODUCTION}

Studio education is the heart and soul of architecture curricula throughout the world. Those of us teaching in this setting have the benefit of unconditional student interest, commitment, and time. But, for too long, the practices of studio formatting and execution have relied on the charrette model of engagement and production; a practice of "exporting into the future" the needed design decision-making. Most often leading to last minute, late night closure of design ideas before they have had time to flourish.

If we are to equip students to function successfully in the quickly-transforming professional practice world of design-for-sustainability, we need to abandon the asymptotic engagement/production curve of the charrette model and instead build the curve of interactive inclusion of both process and content.

This paper summarizes more than a decade of such approach in reconstituting the tutorial education of the studio environment; not only upending the charrette model, but also that of the service delivery phasing of professional practice, from pre-design, programming and site analysis to technical 
representation suitable for construction documents; a sequential phasing that is driven largely by the need to communicate clearly with clients regarding the stages of agreement and closure for which billings can be issued. But which does not serve the education of process and content in design-for-sustainability.

In fact, that linear sequence of topical focus, is challenged by the 4Es of integrative design: "Everybody, Examines, Everything, Early." From day one: all players are at the table, all content areas are identified, and multiple tasks for exploration/research/reporting are laid out in a schedule of blue dot conferencing. That format has become the backbone of success for the studio content shared herein.

As shown in the process graphic provided by Bill Reed (Figure 1) the blue dot identifies those many recursive opportunities to confer with colleagues, to review work completed and to outline next steps; essentially remapping the serial service delivery model as parallel processing activities.

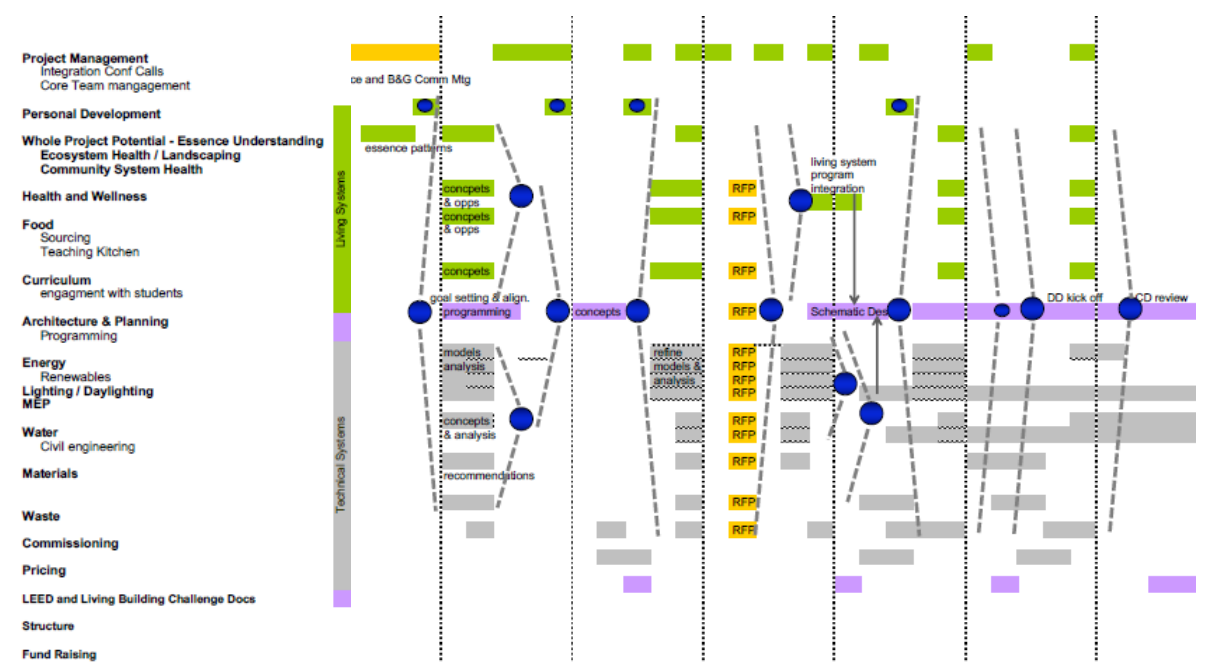

Figure 1. Blue dot reviews with task assignments. Courtesy of: Bill Reed/Regenesis Group.

This very idea has been brought into my studio by providing students, always on the front side, with a list of expected content deliverables and evaluation criteria. And using the schedule of blue dot reviews every two-to-three weeks as a "breathing in/breathing out" rhythm that puts students in control of the interplay of differing influences and factors and the recognition that there is no one (right) way of engaging design.

Rather each student works across scales and content areas, as mapped by initial interests and emerging understandings; this frees each to choose where to enter the design decision space and how to manage the multiple parallel activities needed to achieve design-for-sustainability ideation and development.

In this scenario, the role of the faculty is to keep each student focused on the wholeness of issues to be engaged and reward consistent achievement; as students come to realize that: 1) design is, indeed, a process of intelligent construct and 2) a process that requires a willingness to "fail early and often".

\section{Exploration, Discovery, Application}

To support this dictum, I have found it helpful to initiate each studio with a Nine Stones assignment to invite student exploration, followed by concept introduction, followed by concept application.

As shown in a series of transformations (Figure 2) the opening assignment begins with an exploration in which students have to find a structure within the material nature of the chosen stones and/or bring structure to the organization of those objects in response to an inspiring reference - namely, from Louis Kahn: to explore the idea of architecture as the making of a Society of Rooms. 
Students find organization as either 2-D and/or 3-D manipulations with wide-ranging interpretation of form - both as physical aggregation and in the more penetrating sense of Louis Kahn for whom FORM was the 'order' of architecture; e.g., a library "as an invitation of books", a firehouse "as a street".

After having taken the leap with their exploration, and with an introduction of the vector patterns of force flows in nature, students are asked then to derive an understanding of how their construct can use those environmental factors to shape meaningful qualities of space - individually, or as a Society of Rooms. This task usually jumps to conventional representation of opaque/transparent, open/closed built-form.

Students then are asked to conduct, the application of operational performance simulations, using Sefaira modeling software as both a desk top app to bound interactions and as a web based tool to analyze the sophistication of bundling. At each stage, students are in control of exploration/introduction/application.

\section{Extrapolation}

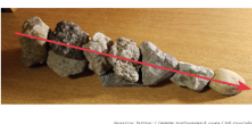

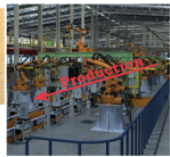

Parts that are ordered with a purpose and are working together
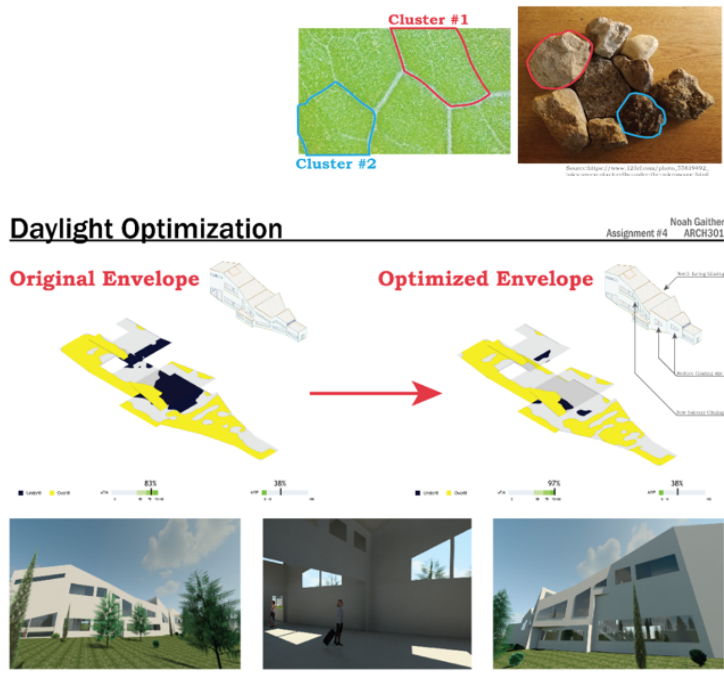

Force Flow Analysis
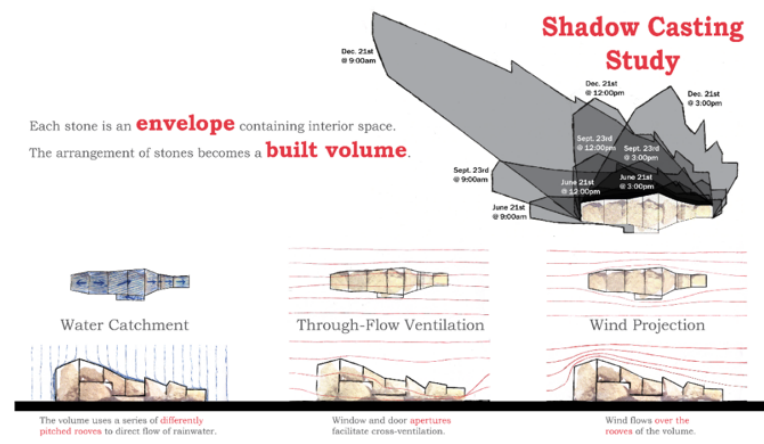

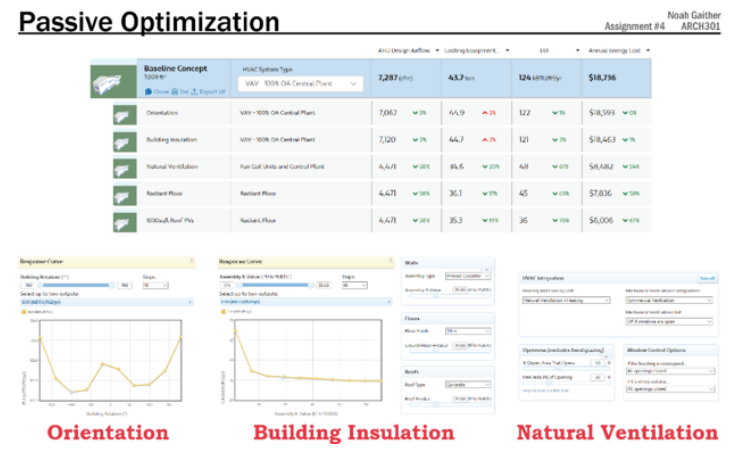

Figure 2. Using nine stones to explore, introduce, and apply the processes and content of design-for-sustainability. Third-Year Student: Noah Gaither 


\section{BUILDING THE CURVE: PROCESS AND CONTENT}

With the experience of the Nine Stones assignments, the students then have a shared understanding from which to build their language of deductive and inductive thinking during the remaining semester.

As shown in Figure 3, the intent of the studio is to "Build the Curve". Rather than relying on delayed, procrastinated and otherwise wasted time, inherent in the conventional charrette model of last-minute production, the upfront clarity of final deliverables and line-item evaluation criteria enable students to achieve a far richer and more fully developed application of design process than otherwise would occur. The lens-like leaf shape between the two curves "contains the content" that otherwise would have been sacrificed for lack of the studio structure presented herein.

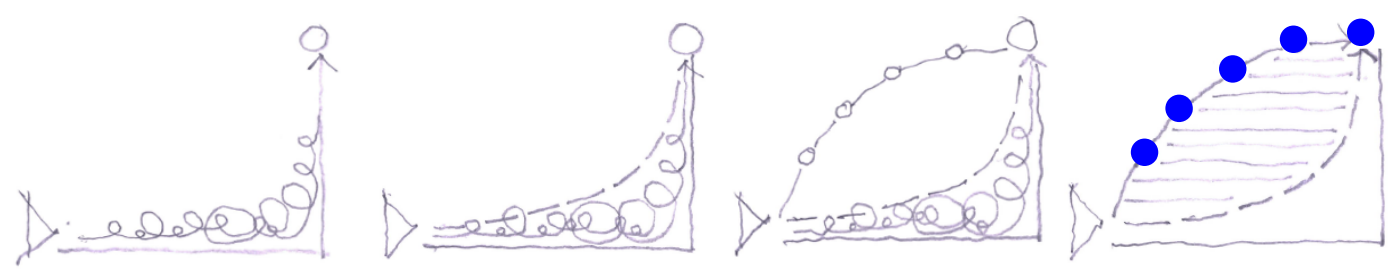

Figure 3. "Building the Curve" of Content beyond the Limits of the Charrette Process in the Design for-Sustainability Studio.

Again, this is reinforced with clear, upfront guidelines which are used at each blue dot review on expected content and presentation format for the close of the project; always including notation on those topics "not yet addressed" and/or "next steps to pursue" as each student works to end-of-semester completion.

As shown in a matrix of assessment (Figure 4) a list of criteria is mandated from day one; everything from organizational diagramming to experiential representation. The content and presentation of projects are evaluated in balance, and over the course of subsequent blue dot reviews, the students "build" their grade.
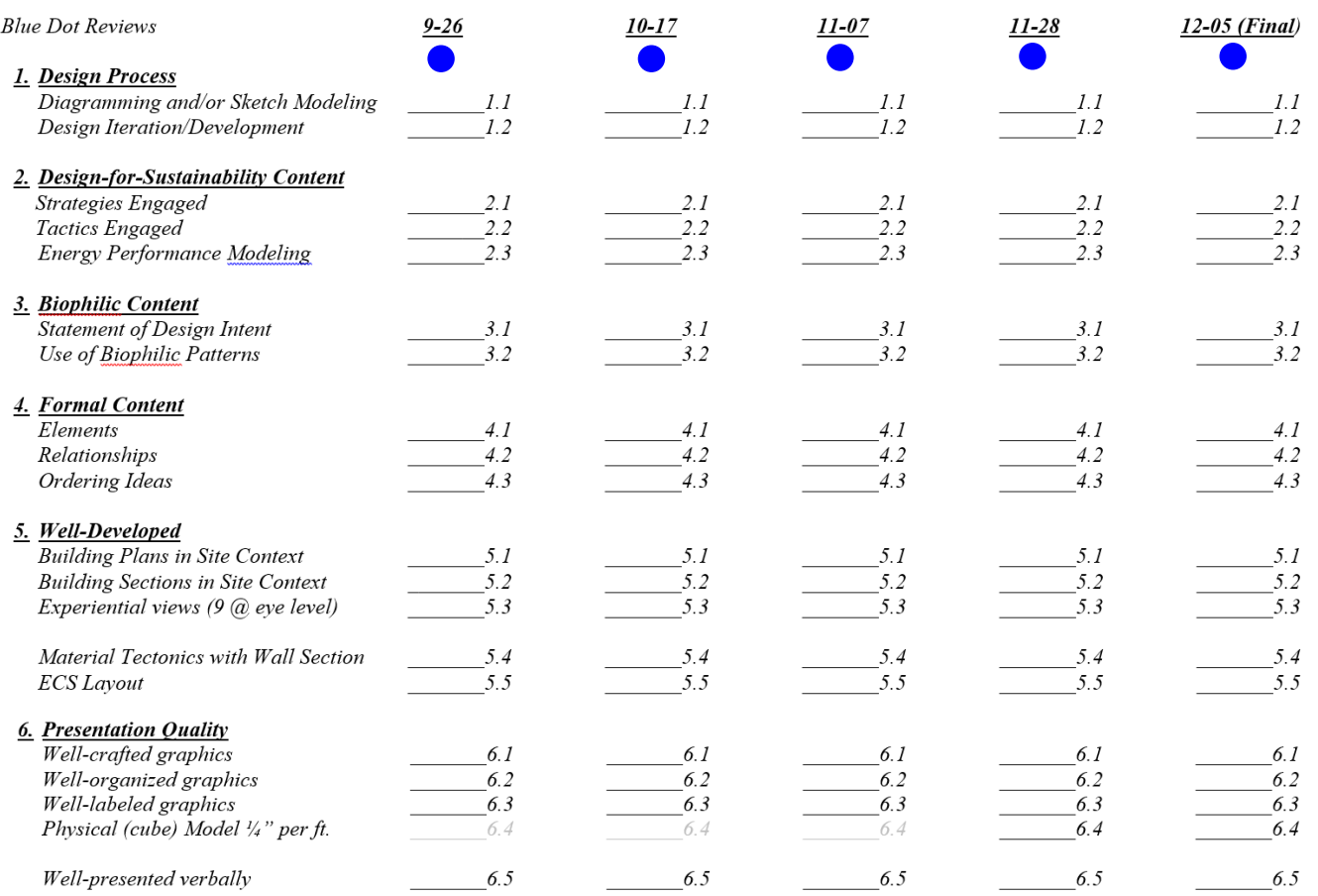

Figure 4. Evaluation Matrix and Blue Dot Scheduling in the Design for-Sustainability Studio. 
This avoids the unfortunate tendency of courses to dampen student enthusiasm by "averaging" early work with later work, wherein, if a student performs inadequately early on, she or he is de facto penalized thereafter; no matter how hard they work, they remain burdened by an early mistake.

Instead, mistakes are encouraged in this studio and students are not penalized for making them. Rather, they are rewarded, in the sense that early missteps and diversions do not "cost" the students in a final evaluation for the semester. Mistakes in fact inform the needed next steps. Students control how they spend their time to compensate for missing content, misdirected exploration, or poor presentation quality - from which they learn and take inspiration. This matrix of grading acknowledges that the design process is healthiest when understood as an inefficient journey of discovery and achievement.

And a key impact of the blue dot reviews is to amplify collateral learning. When seeing content in other student work, which they themselves have not yet engaged, they each can derive insight on how to do so.

Students are encouraged to bring additional criteria to the design experience. This has included quite a range of citations; some assigned, some discovered. They have ranged from the Malcolm Wells Score Sheet, to the Climate Consultant strategic priorities for Psychrometric response, to the AIA COTE Top 10 measures of sustainability. And numerous precedents of celebrated high performing buildings - all of which factor into real-time internet searches during the multiple weekly desk crits. Examples include the host of references in the Architecture 2030 Palette, the Annual COTE Top 10 and the many exemplars found in the seminal SBSE reference works.

Topical lists and diagrammatic representation from many cited sustainability publications as well as the more classic categorization of the "language" of architecture are encouraged. As shown in Figure 5, these can "lead" or "follow" the design development with their inclusion in a final presentation.

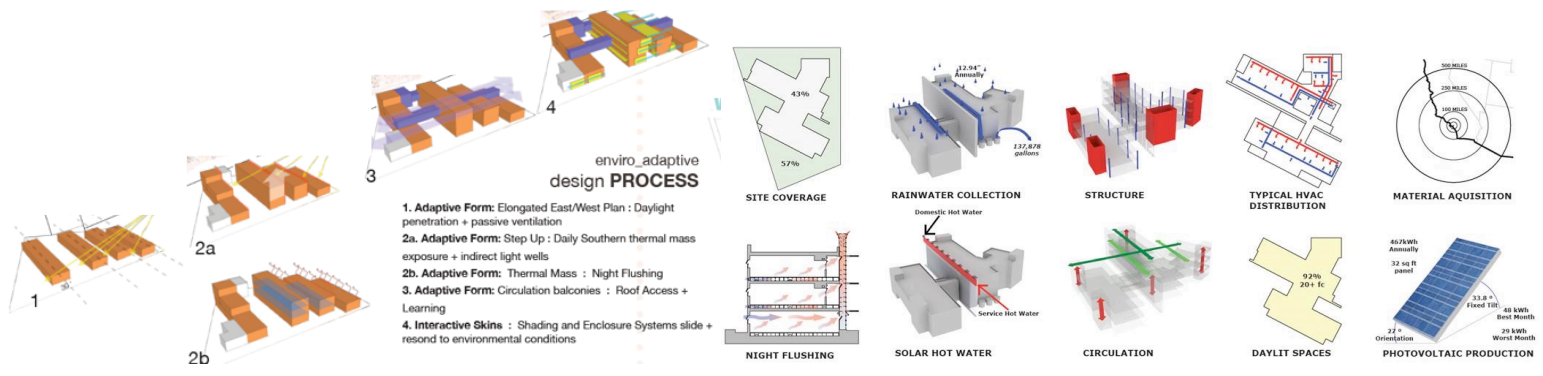

Figure 5. Leading Edge Competition 2010 Fifth-Year Students: Team 1: Chris Rhoads/Amanda Raymond, and Team 2: Andy Hesterman/Erin Chapman/Jason Klinker

As lead-ins, I have found it helpful to identify symbolic, metaphoric and analogic representation.

- A sun path diagram is only a symbol for the existence of the sun - if not translated into plan, section, and transparency/opacity; e.g., "... the building is (not) solar ... because of the diagram."

- An aspiring image can be a metaphor of gestural intent of spatial organization, material use, and/or geometric expression; e.g., "... the building will 'sit' on the land as does a bird on its nest".

- An operational principle of performance in nature can be an analog of biomimetic performance; e.g., "... the building will use stack ventilation modelled on that of a termite mound".

Any topical diagram can be taken through multiple iterations - as a means of opening opportunity. The coincidental alignment/fit then can occur upon reflection; with the indeterminate preceding the resolved. As reinforced in Figure 6 topical explorations are best undertaken as free-body variations; initially distinguishing all that might be possible for each of several design criteria, such as structural materiality and component placement, registration of grid scaling, or wall system opacity, transparency and joinery. 
Such studies depend on recognizing that time can be a friend. By not rushing to final form or obsessing over form alone, these free-body studies assure the chances of finding the logical, complimentary fit of systems of constructability. And when produced using 3-D modeling software can be evaluated best with experiential views, projected operational performance, and tectonic detailing.

In time, students achieve ever more comfort working across scales; often enjoying the change of gears as a means of liberating insight and/or discovering resolution. Switching scales from the cell, to the organ, to the tissue of a construct provides a high order management of design process and content.

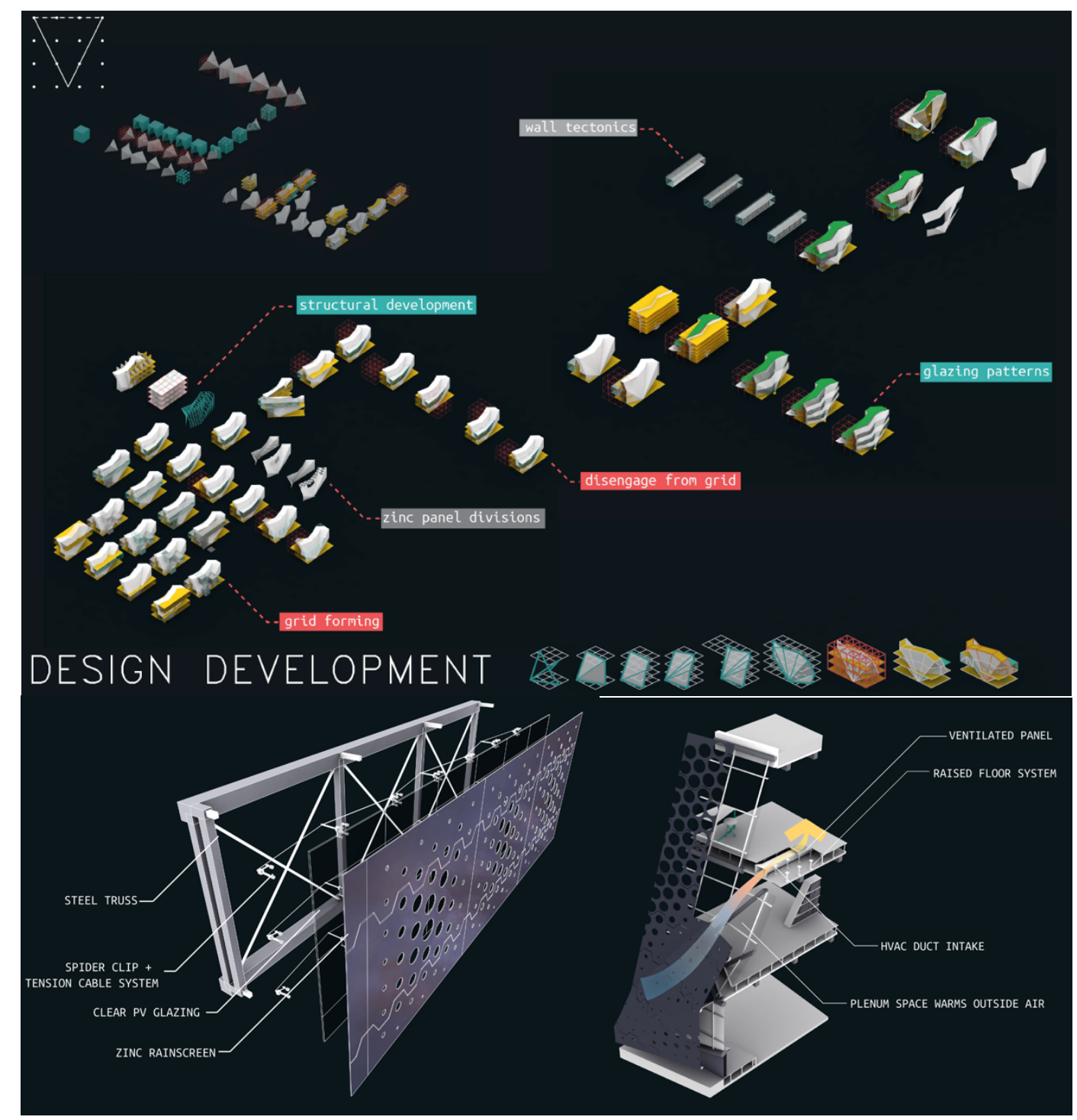

Figure 6. Iterative Studies of a pavilion replacement for Folie P6 in the Parq de la Villette in Paris Third-Year Student: Zack Lensa.

Whether working within a 7-week or 15-week timeframe, the students invoke content areas, and apply (often for the first time) performance software in energy modeling, day-lighting assessment and resource use to readily increment performance projections in real-time and in longer-term bundled simulations. 
Students come to understand the distinction of pattern and sizing, the ordering and muscling of a design, the hierarchy of passive to active design strategy application, the distinction of green, sustainable and generative intervention; i.e., the materiality, sustainability and generative contribution of buildings within ecological settings -- the stocks, flows and yields of optimal system-based performance favored over the optimized efficiencies of separate parts. In short, a whole systems design.
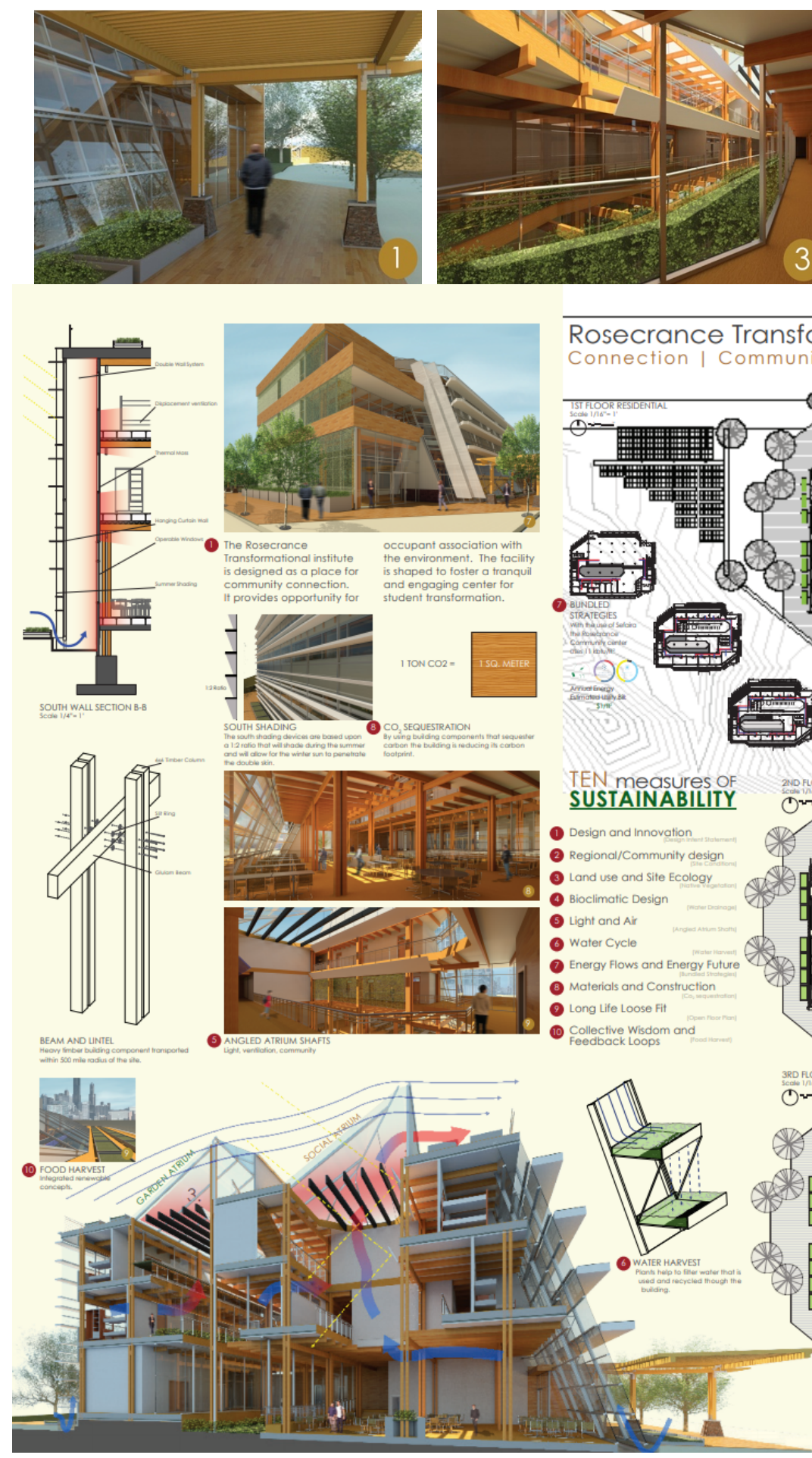

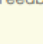

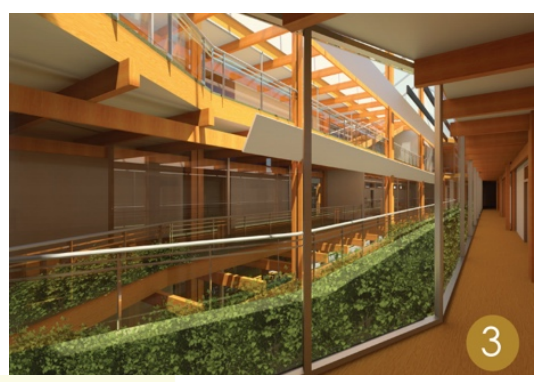

Rosecrance Transformational Institute cnicagou Connection | Community | Tranquility | Engagement
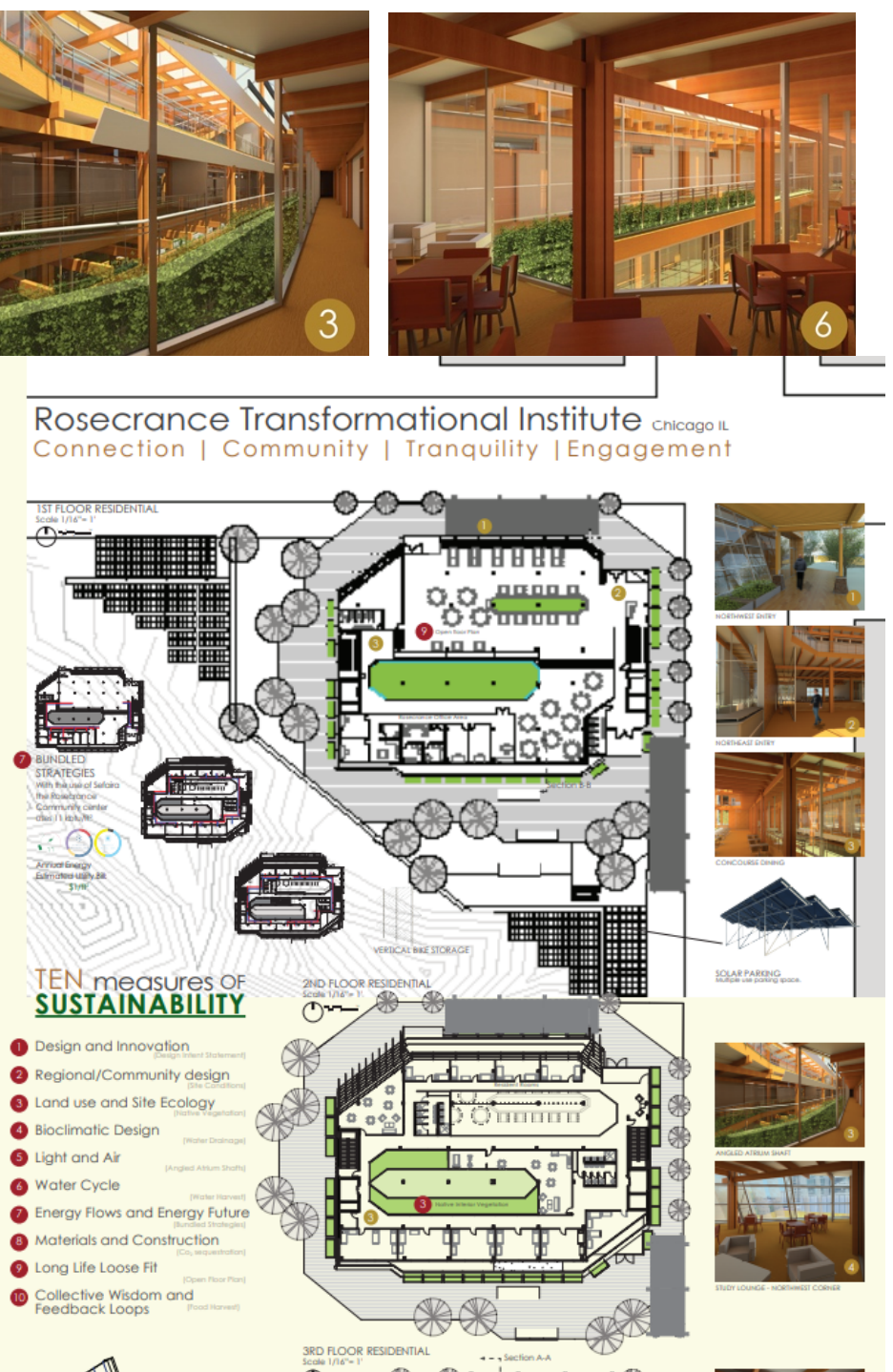

$-1$
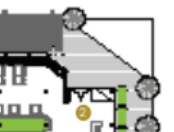
की

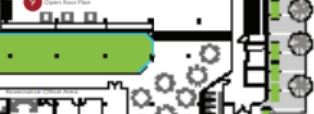

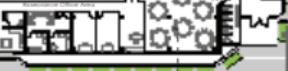

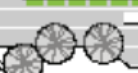
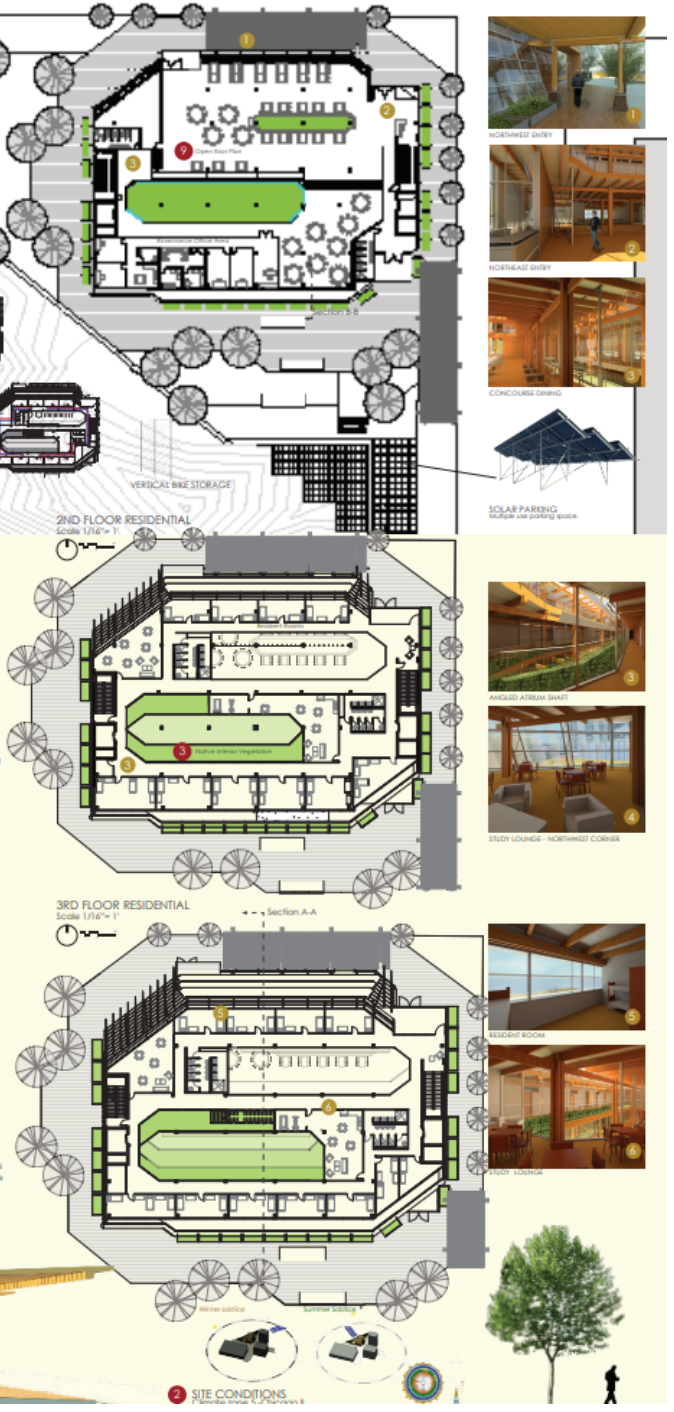

Figure 7. The Rosecrance Transformational Institute, Chicago: Third-Year Student: Sean Costello 


\section{LESSONS LEARNED}
Students respond to:
Students own process through:
Students learn from:
- clarity of purpose
- freedom to initiate
- cohorts over the faculty
- $\quad$ high expectations
- recursive focus
- detailed feedback
- targeted encouragement
- critiquing one another
- third-party juries

The core mission of this Design-for-Sustainability studio - especially appropriate for the third-year in our curriculum - is to enable students to discover that design is a process of aspirational construct. And not a reductionist, lockstep sequence of information gathering and action; so often couched as an exercise in problem-solving. Rather the design process is presented as one of value-creation. As famously observed by the late Louis Kahn, nobody needed Beethoven's Fifth until it existed; it did not solve a problem.

Moreover, students must be encouraged to avoid the trap of postponing engagement under the guise of a "need for more research". And, faculty must avoid the trap of being merely reactionary. e.g., "...go make a thing, bring it back when ready, and I will let you know if I like it - or let me know if/when you do..."

Such traps conspire to yield non-productive wastes of time in which students avoid input from a faculty member, meander about for lack of structural/organizational moorings for their work, and are left to engage in an end-of-time, last-minute decision-making during a sleep-deprived rush to production; which is then presented as a "solution" to the "problem", all wrapped within a "big idea". This is a disservice.

Rather faculty must structure the discovery of the design process within the content of the decision space. In this studio, an inspiring decision space has been essential; over time, students have designed:

- An Institute for the Study and Application of Biophilic Patterns in Brooklyn, NY

- A Rosecrance Transformational Institute to be located in downtown Chicago, $I L$

- $\quad$ Folie for the Paris Accord located in the Parq de la Villette

- An Active learning Center for the Children"s Museum of Indianapolis, IN

- $\quad$ A Green Workforce Training Center for the City of Indianapolis, IN

- An Urban Eco-Block for Detroit, $M I$

- An Intentional "Tall Building" Community in Vancouver, CA

- A 21st Century Library for the City of New Orleans, $L A$

- $\quad$ A Center for Regenerative Studies for numerous domestic and international locations.

Each of these was loaded with aspirational intent, an invitation to dream; a call for vision. But in every case the blue dot structure of the studio setting and faculty/student interaction remained unchanged; Wednesdays used for group critique and blue dot reviews and Mondays and Fridays used for one-on-one feedback; with reflection on progress made and next steps to take.

Without the clarity of expectation on the front side, the rhythmic breathing in and breathing out exercise of frequent reflection, and detailed feedback at the closure of every blue dot review, the level of content engagement and development that has been achieved in each of these projects would not have occurred. 


\title{
CONCLUSION
}

The tutorial education of mentor/mentee interaction is fundamental to all studio courses, but the full impact of studio culture has been found to be best fed by the blue dot technique. As reinforced by Mark Edmundson, a professor of English at the University of Virginia, and the author of "Why Read?"

\begin{abstract}
"A truly memorable college class... is a collaboration between teacher and students. It's a one-time-only event. Learning at its best is a collective enterprise, something we've known since Socrates. You can get knowledge from an Internet course if you're highly motivated to learn. But in real courses the students and teachers come together and create an immediate and vital community of learning...”
\end{abstract}

The blue dot studio structure accommodates the diversity of interests, skills, knowledge, and commitment of students that comprise the typical studio group. It rewards/encourages interaction among the cohorts, provides clear anchoring for that engagement, is totally transparent in its assessment technique, and enables each student to be in charge of her/his own destiny.

Moreover, this model of studio education inherently supports the opportunity for interdisciplinary content integration and could be used in a community setting of multiple instructors working with student groups exposed to all manner of professional disciplinary expertise.

A semester is a long time and a lot of content can be built into the curve. In fact, the same method has been used successfully in half-semester increments when our curriculum has required two differing assignments in a 15 week block of time.

Projects resulting from this studio education have trended toward development of "foreground" signature buildings as a logical reflection of the spirited program briefs as well as genuine interest and curiosity of each and every student, as they self-organize their respective navigation among the moorings of "egocentric" and "eco-centric" interests. ${ }^{1}$

Each student leaves at the close of the semester with an awareness, understanding and ability to exercise deductive and inductive, problem-centered and value-centered methodological structures to frame, engage and evaluate design, to use ordering ideas for development and/or refinement and through their unique, respective, insights - as active learners - can create insightful architecture, as they continue to build the curve of integrated process and content; producing exemplary embodiments of design-for-sustainability, as they learn that design is a process of intelligent construct.

\section{REFERENCES}

AIA Committee on the Environment (COTE) Top Ten Measures https://www.aia.org/resources/6077668the-cote-top-ten-toolkit/

Browning, Bill. 2014. 14 Patterns of Biophilic Design https://www.terrapinbrightgreen.com/report/14-patterns/

Mazria, Edward. 2006. The 2030 Palette. http://www.2030palette.org/

Reed, Bill. 2009. The Integrative Design Guide to Green Building: Redefining the Practice of Sustainability, ${ }^{\text {st }}$ Edition.

\footnotetext{
${ }^{1}$ Longer-term replication at later stages of the studio curriculum can embrace the process and content of design-for-sustainability at the scale of district systems as a foundational "language" of "background" architecture.
} 